\title{
Instrumentos Metodológicos da Análise Econômica do Direito e EFICIÊNCIa das Políticas Públicas Executadas pelo Terceiro Setor
}

\author{
Max Brito Repsold* \\ Benjamin Miranda Tabak**
}

\begin{abstract}
1 Introdução. 2 A reforma administrativa do Estado brasileiro. 2.1 Da administração burocrática à gerencial. 2.1.1 Transferência dos serviços públicos para o setor privado e busca de eficiência administrativa. $3 \mathrm{O}$ terceiro setor. 4 Políticas públicas: breves anotações. 5 Análise econômica do direito, políticas públicas e terceiro setor. 5.1 Elementos da AED - avaliação de políticas públicas e de sua transferência para o terceiro setor. 5.2 Mensuração de custos e de benefícios. 6 Considerações finais. Referências.
\end{abstract}

\section{RESUMO}

O presente artigo tem por objetivo apontar instrumentos metodológicos da Análise Econômica do Direito que podem contribuir para a execução de políticas públicas pelo Terceiro Setor, na busca pela respectiva eficiência. A pesquisa tem como objeto a Reforma do Estado brasileiro e o modelo de administração gerencial adotado na década de 90 (século XX) em substituição ao Estado patrimonialista e à administração burocrática. A globalização é referida como um processo paralelo que indica, em seu contexto, as chaves para o desenvolvimento. Instrumentos metodológicos da Análise Econômica do Direito, relativos à eficiência, são apresentados, bem como critérios que possibilitam a avaliação dos custos e dos benefícios sociais na implementação de políticas públicas.

Palavras-chave: Reforma Administrativa. Análise Econômica do Direito. Políticas Públicas. Terceiro Setor.

\section{INTRODUCุÃO}

Com o capitalismo mundial desenvolvido no Estado-nação por meio de sistemas interestaduais e a virada para o processo de globalização, a ilusão de prosperidade entrou em forte declínio no mundo com a recessão econômica, iniciada na década de 70 (século XX), que lançou o capital corporativo nacional em uma crise sistêmica (ROBINSON, 2010).

* Promotor de Justiça Militar. Membro do MPM. Especialista em Curso de Altos Estudos em Política e Estratégia. Graduado em Direito pela Universidade do Estado do Rio de Janeiro (1997). E-mail: <max.repsold@mpm. mp.br>. https://orcid.org/0000-0001-6070-1456

** Doutor em Economia pela Universidade de Brasília. Mestre em Economia pela Universidade Federal Fluminense. Graduado em Economia pela Universidade Federal de Uberlândia. Professor da Escola de Políticas Públicas e Governo da Fundação Getúlio Vargas (FGV/EPPG). E-mail: <benjaminm.tabak@gmail. com>. https://orcid.org/0000-0002-7935-3188 
Relativamente ao Estado, seu modelo passou, a partir dessa década, a enfrentar crises, principalmente devido à perda de sua capacidade competitiva, ao aumento da inflação e do desemprego, entre outros. Com o crescimento "distorcido", entre outras razões, pela tentativa de não se distinguir da sociedade civil, pretendendo substituir o mercado em vez de complementá-lo, e, com o processo de globalização, que diminuiu a autonomia dos Estados nacionais em relação às políticas econômicas e às sociais, "o Estado entrou em crise (também pelo caráter cíclico da intervenção) e se transformou na principal causa da redução das taxas de crescimento econômico, da elevação das taxas de desemprego e do aumento da taxa de inflação que, desde então, ocorreu em todo o mundo." (PEREIRA, 1997, p. 7-10).

Na década de 80, após a eclosão do endividamento internacional, a atenção do mundo se voltou para a realização de um "ajuste estrutural ou, em termos mais analíticos, o ajuste fiscal e as reformas orientadas para o mercado." (PEREIRA, 2011, p. 21). Nos anos 90, mesmo com esses ajustes, reconhecidamente necessários, a ênfase foi para a necessidade de reforma do Estado, principalmente a administrativa, sendo central a urgência de se reconstruir o Estado e de redefinir o Estado que surgia no mundo globalizado (PEREIRA, 2001a).

Diante disso, no Brasil, na década de 90, foi levada a efeito uma reforma administrativa, orientada pelo modelo liberal, cuja finalidade era superar a crise brasileira, principalmente quanto à condição patrimonialista do Estado (PEREIRA, 2011). Era preciso reconstruir o Estado para que ele "pudesse realizar não apenas suas tarefas clássicas de garantia da propriedade e dos contratos, mas também seu papel de garantidor dos direitos sociais e de promotor da competitividade do seu respectivo país." (PEREIRA, 1997, p. 7).

Essa reforma foi centrada em quatro aspectos: delimitação do tamanho do Estado; redefinição do papel regulador do Estado; recuperação da governança ou da capacidade financeira e administrativa de implementar as decisões políticas; recuperação da governabilidade ou capacidade política do governo de intermediar interesses, garantir legitimidade e governar. Na delimitação do tamanho do Estado, estavam envolvidas as noções de privatização, de publicização e de terceirização (PEREIRA, 2011).

Já quanto à intensificação da globalização - cujas raízes, segundo Sene (2012), remontam à virada do século XV para o XVI, marcando o início do período das Grandes Navegações e da expansão do colonialismo -, agora sob a égide do capitalismo comercial, seu processo possibilita a acumulação da riqueza fundamental para um novo contexto socioeconômico. Esse contexto havia sido transformado por ocasião da primeira Revolução Industrial (século XVII - transição do processo artesanal para a manufatura) e alcançado seu ápice financeiro com a segunda Revolução Industrial (segunda metade do século XIX - desenvolvimento das indústrias químicas, de petróleo e outras). Com a globalização e a evolução da tecnologia da informação, o desenvolvimento alcançou áreas e níveis bem diferentes - a grande transformação da área de energias renováveis e a profunda mudança nas comunicações, entre outros - e passou-se a se falar em “Terceira Revolução Industrial.” (RIFKIN, 2007). 
Emergiram da globalização quatro chaves de desenvolvimento, associadas ao capitalismo globalizado: a primeira se refere a uma nova relação entre capital e trabalho, baseada na desregulação, na informalização e na flexibilização do trabalho; a segunda diz respeito a uma nova etapa de expansão intensiva - esferas públicas e comunitárias que formalmente se encontravam fora da lógica das relações de mercado foram trazidas e inseridas no processo de competição, por meio da privatização, da desregulação estatal e de nova regulação - e extensiva - reincorporação de importantes áreas não tidas como de "primeiro mundo" para a economia capitalista mundial; a terceira foi a criação de uma estrutura legal e regulamentar global, visando a facilitar os novos circuitos de acumulação; a quarta se refere à imposição do modelo neoliberal em países dos chamados "segundo e terceiro" mundo, com programas de ajustes que dessem condição ao livre funcionamento do capital internamente e além das fronteiras (ROBINSON, 2010).

Assim, dos fenômenos citados, crise do Estado e globalização, dois aspectos são destacados respectivamente e constituem o objeto deste trabalho: a reforma do Estado no Brasil e as chaves de desenvolvimento advindas da nova globalização. Isso porque há uma convergência entre uma das estratégias para a delimitação do tamanho do Estado, a terceirização, e uma etapa de expansão intensiva (segunda chave), que trouxe instituições públicas e comunitárias para as relações de mercado, por meio, entre outras, de nova regulação. A síntese desses dois aspectos é a participação da sociedade nas ações públicas do Estado por meio do Terceiro Setor, isto é, "a sociedade civil assumindo a responsabilidade de executar as tarefas que seriam responsabilidade do Estado." (SELEPRIN, 2012, online).

Segundo Bresser Pereira, a Constituição brasileira de 1988 sacramentou os princípios de uma administração pública tão arcaica quanto burocrática.

Uma administração pública altamente centralizada, hierárquica, rígida, fundamentalmente baseada na idéia do controle por processo e não por resultados e objetivos, quando sabemos que administração pública e também a administração de empresas modernas estão hoje baseadas na descentralização, na administração matricial, nos sistemas de autoridade funcional convivendo com os de linha, na confiança, e no controle dos resultados e não dos processos (PEREIRA, 1995, p. 3).

A problemática que surge nesse sentido é quanto à eficiência na realização das políticas públicas com a transferência dessas atividades para o Terceiro Setor. A escassez de recursos leva a se questionar a eficiência dos gastos governamentais a fim de que se busquem novas formas de gestão, o que se reflete diretamente nas políticas públicas. Em consequência, reflete-se também na execução de seus serviços, principalmente os realizados pelo Terceiro Setor, o que leva à necessidade de se identificarem formas ou metodologias que otimizem a decisão sobre essa transferência.

O objetivo deste artigo é apontar aspectos da metodologia da Análise Econômica do Direito que podem contribuir para a execução de políticas públicas pelo Terceiro Setor, na busca pela respectiva eficiência. 
Para tanto, quatro pontos vão ser abordados em seus focos específicos, de modo a contextualizar o propósito deste trabalho: Reforma do Estado, Terceiro Setor, Políticas Públicas e Análise Econômica do Direito.

\section{A REFORMA ADMINISTRATIVA DO ESTADO BRASILEIRO}

Na descrição da Reforma do Estado brasileiro, a globalização é vista em um processo paralelo, entendido como a atual fase da expansão do capitalismo, com fortalecimento do discurso neoliberal decorrente da crise do Estado social e com impacto em diversas áreas, como a economia, a política e a eficiência administrativa.

A alternativa adotada para a retomada do desenvolvimento em um mundo globalizado, em que são refeitas, diariamente, as novas hierarquias políticas e econômicas em escala cada vez mais mundial (BAUMAN, 1999), passa obrigatoriamente pelo corte de custos, seja na área governamental, seja nas empresas privadas (HOBSBAWM, 1995). Firma-se o renascimento do discurso neoliberal, contrário à restrição de mercado e à regulamentação, difundido inicialmente nos Estados Unidos e no Reino Unido e espraiado, posteriormente, para outros países, incluindo os chamados periféricos. Com isso, abriu-se, paulatinamente, a porta do movimento transnacional de capitais, cuja disseminação alcançou níveis até então nunca verificados na história.

Em linhas gerais, o keynesianismo - que defendia a intervenção estatal na economia, mormente nas áreas em que a iniciativa privada não tivesse capacidade ou não desejasse atuar; o equilíbrio entre demanda e capacidade de produção como garantia do emprego pleno; o Estado com papel fundamental no estímulo às economias em crise e em recessão econômica, entre outras - foi enfraquecido com o avanço do neoliberalismo. A globalização impôs a adoção de medidas de abertura econômica pelos países e a pouca interferência do Estado (KEYNESIANISMO, 2017).

Assim, os pressupostos da teoria de Keynes foram substituídos por políticas monetaristas, de desregulamentação da economia e do fluxo de capitais, e o contrato social welfarista foi superado pela lei do mercado. Os Estados se tornaram neoliberais, funcionando, entre outros, para a realização de três serviços essenciais: adoção de medidas fiscais, de políticas monetárias e comerciais que assegurem a estabilidade macroeconômica e a circulação de capitais; fornecimento da infraestrutura básica necessária para desenvolvimento da atividade econômica global; promoção da ordem social, por meio da sustentação de instrumentos de controle (ROBINSON, 2010).

As parcerias público-privadas se inserem nessa perspectiva neoliberal, distribuídas em vários campos das políticas públicas. "O mercado e o setor privado são sinônimos de eficiência, qualidade e equidade. A solução torna-se, então, o Estado mínimo,” reduzido à necessária ação para reprodução do capital (MAZETTO, 2015, p. 4).

É nessa perspectiva, à qual se associa a eficiência, que se enfoca a referida Reforma. 


\subsection{DA ADMINISTRAC̣ÃO BUROCRÁTICA À GERENCIAL}

A formação do Estado brasileiro é resultado do processo histórico de importação e de adaptação da cultura social, política e econômica trazida da Península Ibérica pelos colonizadores, os quais se mesclaram aos índios nativos e aos negros escravizados, bem como aos demais imigrantes posteriormente integrados. $O$ país, assim, sofreu clara interferência dessas origens em sua formação cultural, em seu povo e em sua organização política. Conforme Kossmann (2015), essa herança foi o elemento originário do fortalecimento e dos aproveitamentos dos vínculos e dos interesses interpessoais, além da decorrente confusão entre as relações público-privadas, sempre com prejuízo do público e benefício privado.

Nessa formação histórica, destaca-se o comando do estamento burocrático, definido como um sistema patrimonial que se apropria de oportunidades econômicas, de cargos e de concessões, sem haver nenhuma diferenciação do que é público e do que é privado, e com doações de terra sem obrigação de serviços nem de alienação. Essa estrutura se consolidou, adaptou-se às mudanças que ocorreram e foram incorporadas pela sociedade em sua formação (FAORO, 1997).

Aí se encontram as raízes do patrimonialismo brasileiro, no qual a administração pública estaria, em tese, a serviço de seus agentes ou pessoas a ele relacionadas, e o Estado seria, apenas, um instrumento à disposição dessas classes, para que pudessem retirar dele os maiores benefícios (KOSSMANN, 2015).

Esse modelo vigeu no Brasil durante toda a República, estendendo-se ao período compreendido entre as décadas 50 e 70, quando houve um exitoso processo de industrialização. Porém, esse paradigma passou a sofrer críticas decorrentes de seu grande raio de ação e da intervenção estatal, bem como em virtude de seu aspecto paternalista, como distribuidor das bases materiais de desenvolvimento (HABERMAS, 2012). Conforme destaca Kanté (2009, p. 46), "desse esquema geral resulta, entre outros, o mandonismo, o falseamento do voto, a desorganização dos serviços públicos, [...], pois havia, desde o início, um estado de coisas que asseguraria ao sistema a manutenção de seu poder [...].” O sistema de estamento burocrático persistiu por séculos, pois o patrimonialismo se amolda às transições e às mudanças, mantendo "no corpo estatal os mecanismos de intermediação”, com suas concessões e seus controles.

A administração pública burocrática não tem objetivos claros. Concentra-se na definição de procedimentos para as atividades, nos processos em si e na satisfação das demandas dos cidadãos, sem se preocupar com a eficiência, apenas tentando evitar nepotismos e corrupções. Buscam-se controles preventivos dos procedimentos (PEREIRA, 1998a).

Dessa forma, também a eclosão da crise de endividamento internacional, a crise do Estado propriamente e a globalização impeliram a se buscar "o ajuste estrutural ou, em termos mais analíticos, o ajuste fiscal e as reformas orientadas para o mercado" (PEREIRA, 2011, p. 21), para fazer face às necessidades de adequação à nova fase do capitalismo e à promoção e à garantia dos direitos sociais no país. 
Essa reforma, portanto, surgiu como um novo modelo de administração pública que prima pela qualidade do serviço público em prol do cidadão, usuário dos serviços prestados pelo Estado. Nesse sentido, deve-se ter em conta a necessidade permanente de reorganização das estruturas da administração com ênfase na qualidade e na produtividade do serviço público (CARDOSO, 1995), entre outros que não são foco deste trabalho. Buscou-se, conforme Pereira (1998b), uma proposta de Estado liberal que permitisse sua reconstrução a partir da redução do grau de intervenção estatal na esfera econômica, bem como da transferência, a entidades privadas, de determinados círculos de atuação, anteriormente desenvolvidos diretamente por órgãos e agentes públicos.

É uma reforma gerencial, porque sua inspiração vem da administração de empresas privadas, mesmo que as condições sejam diferentes, pois o interesse é público. Com a nova administração gerencial, busca-se dar condições aos administradores públicos para gerenciarem eficientemente as instituições na realização dos serviços públicos. Essa reforma é democrática, pois se baseia em princípios de democracia, principalmente ante a exigência de mecanismos claros de controle da autoridade e dos resultados. É social-democrática, porque destaca, reafirma o papel do Estado na garantia dos direitos sociais (PEREIRA, 2001b).

Esse modelo de administração se baseia em vários princípios, entre eles: o controle dos resultados; a separação dos formuladores de políticas públicas de seus executores; o estabelecimento da diferença entre o que constitui unidades descentralizadas das atividades estatais exclusivas e o que são serviços sociais competitivos; a transferência desses últimos serviços para o segmento público não estatal ou segmento privado; o controle social direto daquelas unidades descentralizadas, por meio de mecanismos como o contrato de gestão, os indicadores de desempenho e outros; a terceirização de atividades institucionais de apoio, as quais devem ser licitadas no mercado de forma competitiva (PEREIRA, 1997).

Os indicadores devem servir de apoio para detectar as causas e os efeitos de uma ação, e não apenas seus resultados, e podem ser agrupados em categorias que indiquem o grau de controle que a instituição tem sobre eles. Uma avaliação de desempenho deve ter indicadores que meçam, entre outras coisas: Eficácia: em que grau o produto/serviço atende aos padrões estabelecidos, consideradas as demandas de usuários e cliente; Eficiência: em que grau o produto/serviço está sendo produzido a um custo mínimo; Qualidade: em que grau o produto ou serviço é adequado ao uso pelo cidadão/usuário (BRASIL, 1998, p. 28).

No entanto, só os indicadores estabelecidos são não suficientes. Conforme alerta Pereira (2001b, p. 29), "o problema central da reforma não é escolher entre estratégias de gestão, mas criar instituições que viabilizem a adoção dessas estratégias.” No setor privado, cuja definição influi na autonomia de gestão, "o problema das empresas é escolher as estratégias e métodos gerenciais mais adequados.” (PEREIRA, 2001b, p. 29). Já no setor público, a Reforma Gerencial de 1995 tem como objetivo, primordialmente, dar condições de autonomia para que o gerenciamento aconteça. Para isso, as condições institucionais devem ser obrigatoriamente diferentes das que vigem no setor privado, tendo em vista o Estado operar por meio de trans- 
ferências e não de trocas como o setor privado. Sendo assim, "o mecanismo de controle não é o mercado, mas o da política e da administração, e o objetivo não é o lucro” (PEREIRA, 2001b, p. 29). Porém, nada impede que as estratégias entre o público e o privado se assemelhem, desde que a Reforma adote a descentralização e dê autonomia às agências do Estado, ao mesmo tempo, definindo indicadores de desempenho para as organizações e criando o mecanismo do controle social para seu controle, além do controle gerencial por resultados (PEREIRA, 2001b).

A administração gerencial já enfatiza a descentralização e os controles a posteriori dos resultados. Os mecanismos desses controles é que vão permitir a realização de ajustes ou correções ao longo do processo, para que os objetivos sejam alcançados tal como previstos. Esses mecanismos buscam, principalmente, assegurar a aplicação dos recursos de forma adequada e regular. O controle visa também à transparência na gestão pública (BARBOSA, 2002).

A Reforma Gerencial envolve a transferência de tarefas que podiam ser desenvolvidas pelo mercado, como serviços que não caracterizam o exercício do poder pelo Estado - como educação, saúde, cultura e pesquisa científica - para o setor privado e para o setor público não estatal (BRASIL, 1997), desobrigando-o de diversas funções na área econômica e de prestação de serviço. Isso em razão do reconhecimento das deficiências governamentais para promover valores comuns e de aceitação dos mercados, dos direitos de propriedade e dos mecanismos de preço (MITCHELL, 2003).

O alerta de Bresser Pereira e a explicação de Barbosa sobre uma das propostas da Reforma Gerencial constituem a problemática que ensejou o objetivo deste trabalho que é: apontar aspectos da metodologia da Análise Econômica do Direito que podem contribuir para a execução de políticas públicas pelo Terceiro Setor, na busca pela respectiva eficiência.

\subsubsection{Transferência dos serviços públicos para o setor privado e busca de eficiência administrativa}

A necessidade da redefinição da atuação governamental, como já dito, foi objeto de uma nova concepção de Estado e de outro paradigma, fruto da corrente neoliberal que se estendeu por diversos países, atingindo o Brasil no final do século XX (ROBINSON, 2010).

O liberalismo tem duas posturas no que diz respeito às diferenças sociais: uma posição conformista, em face das ocorrências da vida privada, entendendo ser decorrente das diferenças naturais entre os agentes; a vedação a qualquer intervenção do Estado, inclusive na proteção dos mais vulneráveis. Dessa forma, as ações para suprir necessidades seriam aquelas provenientes do mercado ou das organizações e estariam na perspectiva do progresso econômico (STRAPASSON; PAMPLONA, 2014), uma vez que o Estado não consegue manejar satisfatoriamente os meios de que dispõe para a consecução de seus objetivos e é visto como um bem em si mesmo, desvinculado do interesse público que deveria pautar sua atuação (PEREIRA, 2011). 
Diversos diplomas legais buscaram regulamentar a realização dos serviços públicos por entidades privadas, quer do Segundo Setor (mercado), quer do Terceiro Setor (as organizações): Lei no 8.031, de 1990, revogada pela Lei no 9.491, de 1997, que disciplina o Programa Nacional de Desestatização; a Lei no 8.987 , de 1995, que trata da concessão e permissão da prestação de serviços públicos; a Lei no 9.074, de 1995, que estabelece normas para outorga e prorrogações das concessões e permissões de serviços públicos; a Lei no 11.079, de 2004, que normatiza a parceria público-privada.

No que se refere ao Terceiro Setor, a Lei no 9.637, de 1998, dispõe sobre a qualificação de entidades como organizações sociais; a Lei $\mathrm{n}^{\circ}$ 9.790, de 1999, estabelece a qualificação de pessoas jurídicas de direito privado, sem fins lucrativos, como Organizações da Sociedade Civil de Interesse Público; a Lei no 13.019, de 2014, define o regime jurídico das parcerias entre a administração pública e as organizações da sociedade civil. Essas leis formam o arcabouço legal que permite à administração pública transferir a execução de serviços públicos àqueles entes privados.

Especificamente sobre a Lei no 9.637, de 1998, foi proposta a Ação Direta de Inconstitucionalidade (ADIN) no 1.923/DF, na qual se buscou a declaração de inconstitucionalidade da Lei no 9.637/98 e, igualmente, da inovação do inciso XXIV do art. 24 da Lei no 8.666/93 (Lei de Licitações), acrescentado pela Lei no 9.648/98. Os argumentos levantados referiram-se ao fato de se transferirem responsabilidades do Poder Público para o setor privado (BRITO, 2016). Assim, o principal foco da ADIN no 1.923 /DF foi verificar se a norma constitucional teria fixado uma concepção de Estado e, dessa forma, estabelecido um paradigma institucional para a administração pública.

O Supremo Tribunal Federal julgou parcialmente procedentes os pedidos, dando interpretação, conforme a Constituição, à Lei no 9.637/98, bem como à modificação introduzida pela Lei no 9.648/98 ao artigo 24 XXIV da Lei no 8.666/93. Ficou decidido que essa Corte Constitucional estava impedida de atuar de forma a engessar e a cristalizar "um determinado modelo pré-concebido de Estado, impedindo que, nos limites constitucionalmente assegurados, as maiorias políticas prevalecentes no jogo democrático pluralista possam pôr em prática seus projetos de governo." (BRASIL, 2015, p. 2). Decidiu-se, ainda, sobre a possibilidade jurídica da contratação do Estado com entidades da sociedade civil, desde que elas sejam qualificadas como "organizações sociais", para prestação dos serviços objeto da Lei no 9.637/98. Também devem ser observados os princípios determinantes da administração pública para a respectiva qualificação, celebração do contrato de gestão, dispensa de licitação para contratações e outorga de permissão de uso de bem público e seleção de pessoal pelas organizações sociais (BRITO, 2016). Decidiu-se, ainda, afastar qualquer interpretação que restrinja o controle, seja pelo Ministério Público e pelo Tribunal de Contas da União, da aplicação de verbas públicas.

Embora tenha sido objeto de críticas e de resistências e tenha sofrido um processo de contenção judicial e de mitigação de resultados, verificando-se inclusive seu recuo no início 
dos anos 2000, os efeitos da Reforma do Estado nesse sentido são notados nas recentes administrações. Isso principalmente em decorrência da edição da Lei no 13.019, de 2014 - que estabelece o regime jurídico das parcerias entre a administração pública e as organizações da sociedade civil - e do julgamento da ADIN 1923/DF, que confirmou a possibilidade de transferência da execução de serviços públicos para entidades do Terceiro Setor.

\section{O TERCEIRO SETOR}

No Brasil, a partir dos anos 70, começou a crescer de importância um novo ator social, o qual passou a ser denominado Terceiro Setor, definido como o conjunto de agentes privados com fins públicos, cujos programas "visavam atender direitos sociais básicos e combater a exclusão social e, mais recentemente, proteger o patrimônio ecológico brasileiro." (SZAZI, 2003, p. 22). São organizações cujos objetivos principais são sociais em vez de econômicos (HUDSON, 1999).

O surgimento do denominado Terceiro Setor está relacionado com as já referidas transformações no mercado e na sociedade, que conduziram a uma nova distribuição dos papéis de cada ente social no alcance do bem comum. E nesse sentido, progressivamente, a sociedade civil organizada, por meio de organizações e/ou associações, passou a assumir responsabilidades pela proteção e defesa de direitos, antes cingidos à órbita do Estado (Primeiro Setor).

Nessa conjuntura, há organizações com personalidade de direito privado que ocupam “ao menos em tese uma posição intermediária que lhes permita prestar serviços de interesse social sem as limitações do Estado, nem sempre evitáveis, e as ambições do Mercado, muitas vezes inaceitáveis.” (PAES, 2013, p. 82). São entidades que não se encontram na estrutura da administração pública, mas que, em razão da possibilidade de poderem receber e gerir recursos públicos para o desenvolvimento de atividades específicas e de interesse social, ganharam relevância como instrumentos para a consecução dos objetivos do Estado. Nessa classificação, situam-se as Organizações Civis (OS), as Organizações Sociais de Interesse Público (OCIP), as cooperativas, as associações, as fundações e o trabalho voluntário, além das entidades sindicais e religiosas e as também chamadas Organizações Não Governamentais (ONGs) (BALAZEIRO, 2016).

Tais organizações, em sentido amplo, foram concebidas dentro do conceito de administração gerencial, e o Ministro Luiz Fux, após comentar sobre a questão legal dessas entidades em seu voto no julgamento da referida ADIN 1.923, afirmou que saber em quais situações a atuação privada pode ser mais eficiente que a pública depende da "moldura constitucionalmente fixada para a atuação dos poderes públicos, em campos sensíveis, como saúde, educação, cultura, desporto e lazer, meio ambiente e ciência e tecnologia, referidos no art. 1 da Lei no 9.637/98.” (BRASIL, 2015, p. 13).

Dentro dos pressupostos da administração gerencial, inicialmente, pode-se tomar como ponto norteador dessa moldura o princípio da eficiência na administração pública, introdu- 
zido por meio da Emenda Constitucional no 19/1998 no rol daqueles elencados no caput do artigo 37 da Constituição Federal de 1988. A finalidade foi orientar a atuação pública no novo contexto da administração gerencial, retirando dos órgãos governamentais as incumbências para as quais sua presença não fosse imprescindível. Privilegiou-se a gestão por metas e resultados com menores custos, "ou seja, fazer mais e melhor com menos." (KOSSMANN, 2015, p. 83). O Terceiro Setor, então, no exercício de atividades de responsabilidade do Estado, submete-se às mesmas exigências de eficiência que as realizadas diretamente por este.

Embora carecendo de uma legislação sistematizada para o Terceiro Setor, as Leis no 9.637, de 1998, e nº 9.790, de 1999, respectivamente das organizações sociais e das organizações da sociedade civil de interesse público, permitem maior participação dessas entidades privadas no planejamento, na direção e na execução de projetos sociais. A Lei no 13.019/14 - denominada o novo marco regulatório do Terceiro Setor - e as modificações que foram dadas pela Lei no 12.204/15 criaram o regime jurídico das parcerias entre a administração pública e as organizações da sociedade civil, com priorização do controle de resultados, indicando que seu foco deve estar centrado na verificação do cumprimento do objeto e do alcance dos resultados (controle de fins), embora também seja necessário analisar as despesas e as formas de execução do objeto (controle de meios).

Verifica-se que o ordenamento normativo vem buscando meios de aperfeiçoar a forma como o Estado transfere aos entes privados a execução de serviços de sua titularidade, com objetivo de torná-lo mais enxuto e eficiente para a consecução de seus fins, dentro de uma concepção gerencial. A reconstrução da sociedade civil diz respeito a um novo arranjo a ser dado assim pelos dois sistemas - o Estado e o mercado - "e supõe que não se possa mais subsumir o público ao privado, como ocorreu no período da modernidade e nos paradigmas do direito formal burguês (Estado Liberal) e do direito materializado do Estado Social.” (DIAS, 2008, p. 95).

Para o Ministério da Administração Federal e Reforma do Estado (MARE), o Terceiro Setor vem se fortalecendo "institucionalmente para colaborar de forma cada vez mais ativa na produção de bens públicos. A reforma do Estado não é, assim, um tema abstrato: ao contrário, é algo cobrado e iniciado pela sociedade, que vê frustradas suas demandas e expectativas." (BRASIL, 1997, p. 8).

Mas Mazetto afirma que "a compreensão das parcerias público-privadas exige um aprofundamento da noção de políticas públicas, que por sua vez só se tornam devidamente transparentes pela apreensão das teorias políticas que sustentam as formas de Estado no capitalismo." (MAZETTO, 2015, p. 8).

\section{POLÍTICAS PÚBLICAS: BREVES ANOTAÇÕES}

No Brasil, as políticas públicas foram concebidas nos anos 90 como uma das razões das reformas estruturais e sociais nos ambientes econômico e institucional, "ligadas tanto ao 
novo conjunto de políticas macroeconômicas adotado, quanto à implementação de reformas de cunho liberalizante." (YANO; MONTEIRO, 2008, online). O objetivo seria estabelecer condições para a retomada do crescimento da economia, de forma que a crise, referida anteriormente, fosse superada.

Para tal, é necessário o perfeito delineamento de todas as variáveis que influenciam a execução das políticas públicas (políticas, sociais, culturais), bem como a previsão do impacto das ações, pois a pressão pela solução do problema pode fazer que a resposta do Estado apresente traços diferentes dos resultados esperados. Esses traços podem envolver omissões de pontos fundamentais, como a sustentabilidade da população envolvida, aspectos que fazem que essas políticas não se transformem em políticas assistenciais (KANTÉ, 2009).

$\mathrm{Na}$ conceituação das políticas públicas, vários enfoques vão conformando o todo de seu conteúdo e de sua sistemática. Políticas públicas são "conjuntos de programas, ações e atividades desenvolvidas pelo Estado diretamente ou indiretamente" (PARANÁ, 2018, online), contando, para tanto, com a participação de entes públicos e privados. Elas buscam assegurar um direito determinado aos cidadãos, de forma difusa, ou a um "determinado seguimento social, cultural, étnico ou econômico." (PARANÁ, 2018, online). São direitos garantidos constitucionalmente ou reconhecidos por parte da sociedade e pelos poderes públicos, no caso de novos direitos das pessoas ou comunidade (PARANÁ, 2018).

Trata-se de um fluxo de decisões públicas, orientado a manter o equilíbrio social ou a introduzir desequilíbrios destinados a modificar essa realidade. Decisões condicionadas pelo próprio fluxo e pelas reações e modificações que elas provocam no tecido social, bem como pelos valores, idéias e visões dos que adotam ou influem na decisão. É possível considerá-las como estratégias que apontam para diversos fins, todos eles, de alguma forma, desejados pelos diversos grupos que participam do processo decisório (SARAVIA, 2006a, p. 28).

Conforme Rua, políticas públicas compreendem o conjunto das decisões e de ações relativas à alocação imperativa de recursos. São políticas públicas e não coletivas, sendo sua dimensão pública dada não pelo tamanho do agregado social sobre o qual incidem, mas pelo seu caráter imperativo. "Isto significa que uma das suas características centrais é o fato de que são decisões e ações revestidas da autoridade soberana do poder público.” (RUA, 1997, p. 2).

Em seu percurso, as políticas públicas podem ser originadas de demandas geradas tanto dentro do próprio sistema político como reivindicações de bens e serviços, como saúde, educação, transportes e outros - como do sistema de suporte - obediência às leis e aos regulamentos, participação política ou votar em apoio a algum partido (EASTON, 1970). Decorrem de demandas de segmentos da população, as quais são direcionadas para o sistema político ou para a classe dominante, e seus atores pressionam o Estado para orientá-las de acordo com seus interesses (LUSTOSA, 2006).

O fundamento das políticas públicas, que justifica seu aparecimento, é a própria existência dos direitos sociais, isto é, aqueles que, inseridos no rol de direitos fundamentais do homem, concretizam-se por meio de prestações positivas do Estado. É a "função estatal de 
coordenar as ações públicas (serviços públicos) e privadas para a realização de direitos dos cidadãos - à saúde, à habitação, à previdência, à educação", legitimada pelo convencimento da sociedade quanto à necessidade de realização desses direitos sociais (BUCCI, 1997, p. 90).

Os problemas a serem solucionados por meio de políticas públicas, inicialmente, compõem a agenda do governo, que avalia sua importância e "analisa as razões que levam a incorporação dos problemas à lista de prioridades da ação pública, bem como os elementos que devem ser considerados no processo de formação da agenda.” (SARAVIA, 2006b, p. 15). Reconhecido o problema, busca-se depois o caminho definitivo para sua solução, formalizando-se essa decisão, o que significa estabelecer as normas que vão possibilitar a implementação da política pública pelos diversos atores envolvidos. "É que essas normas cumpram os requisitos de clareza e precisão, que permitirão atingir os objetivos desejados.” (SARAVIA, 2006b, p. 16).

Conforme Lustosa (2006), o processo de formulação de uma política é cheio de debates intensos e de grande carga político-ideológica. Sua implementação ocorre por meio de planos, de programas e de projetos. "O plano é a representação da política, é o produto do processo pelo qual um ator seleciona uma cadeia de ações para alcançar seus objetivos.” (LUSTOSA, 2006, p. 3).

Inclusive, Rua (1997) explica que há pré-condições para uma política pública ser perfeitamente implementada:

a) não deve haver restrições ou desvirtuação por circunstâncias externas à agência implementadora;

b) o tempo e os recursos devem ser suficientes;

c) cada etapa da implementação deve combinar os recursos necessários a sua realização;

d) a política deve basear-se em uma relação entre a causa e o efeito;

e) essa relação deve ser direta, admitindo-se fatores intervenientes mínimos;

f) apenas uma agência deve implementar uma política, com um mínimo de dependência de outros entes em número e importância;

g) os objetivos a serem alcançados devem ser completamente compreendidos, havendo consenso quanto a isso;

h) na direção dos objetivos, deve ser possível especificar detalhadamente e em sequência as respectivas tarefas de cada participante;

i) a comunicação entre os vários elementos envolvidos deve ser perfeita;

j) os atores do comando devem ser capazes de obter obediência dos comandados (RUA, 1997).

Especialmente no que diz respeito às relações interinstitucionais envolvidas no processo das políticas públicas, principalmente em sua implementação,

Há ações desencontradas, pois muitas vezes diversos órgãos realizam ações separadamente para um mesmo objetivo, sendo empregados recursos financeiros e humanos em duplicidade para um mesmo fim. E o controle dessas ações é difícil, porque o país é muito grande, e a gestão, em nível geral, termina envolvendo problemas de autoridade. A criação de uma nova instituição exigiria o 
estabelecimento de uma administração própria, com poderes para estabelecer prioridades, para coordenar as ações entre as instituições, para controlar e avaliar tais ações (KANTÉ, 2009, p. 26).

É importante acrescentar o resultado de análises feitas por pesquisadores sobre o percurso das políticas públicas no Brasil, como forma de demonstrar o que ele implica, quando elas são implementadas pelo poder público, e o que as organizações do Terceiro Setor vão ter de solucionar ou aprimorar no processo.

Os resultados são distintos e envolvem várias etapas desse processo. De acordo com Arretche, primeiramente, há um descompasso entre o tempo da formulação/decisões públicas e o da respectiva implementação e resultados, ou seja, em tese, o tempo demandado para os resultados não é alcançado. Essa autora também explica que há deficiência por parte dos locais onde as políticas devem ser implantadas e que essa deficiência nem sempre é de responsabilidade de governos locais ou estaduais, sendo, até mesmo, do governo federal (ARRETCHE, 2006).

Costa afirma que a implementação das políticas públicas ocorre em um ambiente de pluralidade de atores, indo desde instituições públicas até os beneficiários, entre funcionários e técnicos que atuam. Os locais para os quais os objetivos se direcionam geralmente são precários quanto às condições econômicas e sociais. Por isso, ele resume que as ações dessa implementação são expostas a outros fatores externos que envolvem até negociações, as quais podem modificar algum conteúdo da política; há uma baixa capacidade estrutural e organizacional, principalmente nos municípios, para dar suporte às ações; falta de conhecimento do objetivo das ações e de seu foco específico; atores, muitas vezes, utilizam estratégias que atendam mais a seus interesses, o que também é difícil de controlar (COSTA, 2002).

Em síntese, a responsabilidade pela implementação de políticas públicas envolve quatro variáveis importantes:

a) a natureza da política: não pode admitir ambiguidades;

b) a estrutura de implementação: os elos da cadeia devem ser mínimos;

c) a prevenção de interferências externas;

d) o controle sobre os atores envolvidos na implementação.

Quanto a esse último aspecto, devem ser desenvolvidas ferramentas orientadas para essa finalidade de controle, e os instrumentos da Análise Econômica do Direito podem ser perfeitamente aplicados.

\section{ANÁliSE ECONÔMICA DO DIREITO, POLÍTICAS PÚBliCAS E TERCEIRO SETOR}

Na década de 70, em contraposição à visão predominante na teoria jurídica, há o surgimento de tendências ou movimentos intelectuais que visam ao estudo multidisciplinar do direito, entre as quais a Law and Economics ou Análise Econômica do Direito (AED), 
que propõe a análise do Direito sob a perspectiva econômica (ALVAREZ, 2006). Trata-se de um movimento contemporâneo que combina as ciências econômica e jurídica em uma tentativa de estudo interdisciplinar, tendo como característica comum a aplicação de teoria microeconômica do bem-estar para analisar e reformular tanto as instituições particulares como o sistema jurídico em seu conjunto (MERCADO, 1994).

Gico Júnior (2010), em suas abordagens, conceitua a AED como

A aplicação do instrumental analítico e empírico da economia, em especial da microeconomia e da economia do bem-estar social, para se tentar compreender, explicar e prever as implicações fáticas do ordenamento jurídico, bem como da lógica (racionalidade) do próprio ordenamento jurídico. Em outras palavras, a AED é a utilização da abordagem econômica para tentar compreender o direito no mundo e o mundo no direito. A AED tem por característica a aplicação da metodologia econômica a todas as áreas do direito, de contratos a constitucional, de regulação a processo civil, de direito ambiental a família e é justamente essa amplitude de aplicação que qualifica uma abordagem AED da simples aplicação de conhecimentos econômicos em áreas tradicionalmente associadas à economia (GICO JUNIOR, 2010, p. 11).

A aplicação da AED na avaliação das políticas públicas, cuja execução seja transferida para o Terceiro Setor, insere-se nessa finalidade de regulação de um processo que é civil, que é econômico e que envolve direitos.

No caso deste trabalho, apresentam-se elementos da AED que podem contribuir para a avaliação das políticas públicas em si, desde a respectiva decisão, até a perspectiva de transferência de sua implementação para o Terceiro Setor.

\subsection{ELEMENTOS DA AED - AVALIAÇÃO DE POLÍTICAS PÚBLICAS E DE SUA TRANSFERENNCIA PARA O TERCEIRO SETOR}

A AED se mostra útil à realidade jurídica, ao propor um instrumental teórico para a compreensão dos fatos sociais e, principalmente, de como os agentes sociais respondem às alterações nas políticas elaboradas pelo governo (GICO JUNIOR, 2010). A aplicação das leis deve trazer a máxima satisfação "gerando o menor custo na alocação de riquezas." (CARDOSO, 2015, p. 298). As regras jurídicas são concebidas, nessa perspectiva, em uma feição instrumental, voltadas para a solução eficiente.

No que tange às políticas públicas implementadas pelo Terceiro Setor, conforme Pereira (1999), o problema é saber quais funções e competências devem permanecer no âmbito da administração direta do Estado e quais vão ser transferidas para outras entidades. Esse problema talvez encontre em paralelo a problemática de Coase, declarada há várias décadas, sobre o que é uma empresa e que tamanho ela deve ter, haja vista ela poder desempenhar competências acrescidas dentro da sua hierarquia interna ou utilizar o mercado, ou seja, subcontratar outras empresas para as respectivas atividades. $\mathrm{O}$ que subsidia a decisão do gestor tem a ver com os custos de transação, uma vez que, sendo mais barato subcontratar 
ou adquirir no mercado do que produzir internamente, a empresa deve fazê-lo. Essas ideias de Coase influenciaram uma geração de pensadores nas áreas do direito e da economia, para os quais os custos de transação passam a desempenhar papel relevante na avaliação das leis e das políticas públicas.

Nos custos de uma transação, verificam-se assimetrias informacionais, custos de barganha, custos legais e custos de busca (TABAK, 2015). A abordagem econômica do direito permite ao administrador compreender tanto as leis como as contingências para adoção de comportamentos. Permite, ainda, utilizar instrumentos para a consecução dos objetivos pretendidos na execução das políticas públicas, no que concerne à eficiência e à distribuição. A implementação de políticas eficientes tem como base a distribuição da justiça (CARDOSO, 2015).

A análise e a decisão sobre quais funções devem permanecer no âmbito da administração e quais podem ser delegadas ao Terceiro Setor depende de um conjunto de fatores que, por vezes, podem estar incluídos no conceito da AED, uma vez que o administrador deve evitar condutas oportunistas com a utilização irregular dos recursos e a captura do interesse público pelo privado.

Também deve levar em consideração que os homens agem como seres racionais, devendo o administrador precaver-se daquilo a que Silva (2015) se refere, com base nos conceitos de Oliver Wendell Holmes Jr., sobre good man e bad man. Para Silva, o primeiro tipo age em respeito às regras de sua consciência e às normas éticas, e o segundo, embora não se refira a um indivíduo perverso ou de má índole, aparenta desapego às regras morais e direciona sua conduta para evitar consequências legais e sanções que lhe possam ser aplicadas (HOLMES JUNIOR, 1897).

Não pode o administrador público descurar-se das precauções devidas nos ajustes e nos contratos fixados com os entes privados, e sim buscar uma forma criativa de gerar competição em mercados, dentro de um setor tipicamente monopolista, como o de oferta de infraestrutura.

A melhoria na gestão dos recursos públicos no Brasil faz-se urgente. O Instituto Brasileiro de Planejamento e Tributação (IBPT) lançou, em 2013, a terceira versão de seu estudo sobre a carga tributária brasileira versus o Índice de Desenvolvimento Humano (IDH), na perspectiva do correspondente retorno à população em forma de condições de vida. Entre os resultados obtidos, viu-se que, entre os 30 países de maior carga tributária, o Brasil ocupa o pior lugar quanto ao retorno para sociedade, em termos de bem-estar, dos valores arrecadados (FOLLONI; YAZBEK, 2013).

O decisor público deve levar em consideração o termo ótimo para a atividade administrativa e a AED ou law and economics, cujo argumento central é o de que os conceitos econômicos são úteis para a análise do direito e que os agentes econômicos os levam em consideração para tomar suas decisões, para maximizar seus benefícios e sujeitar-se ao menor custo possível (TABAK, 2015). Para tanto, a AED centra-se em três princípios basilares: escolha racional ou maximização, equilíbrio e eficiência, os quais se qualificam como ferramenta à disposição dos 
órgãos governamentais na escolha ideal da política pública (GONÇALVES; RIBEIRO, 2013). O princípio da escolha racional ou maximização se baseia na noção de que os indivíduos são racionais e fazem escolhas que atendam a seus interesses pessoais, sejam eles quais forem, calculando os custos e os benefícios de suas decisões (SILVA; AGUIAR; TABAK, 2015). O princípio do equilíbrio se refere ao padrão comportamental que se atinge quando todos os atores estão maximizando seus próprios interesses simultaneamente. Em termos jurídicos, uma norma será mais eficiente que outra se for capaz de atingir os mesmos resultados por meio de custos menores (GONÇALVES; RIBEIRO, 2013). O princípio da eficiência de Kaldor-Hicks, por sua vez, parte da premissa de que as normas devem ser planejadas com o objetivo de causar o máximo bem-estar ao maior número de pessoas, de modo que os ganhos totais compensem as eventuais perdas sofridas por alguns. Assim, o desenvolvimento e a implementação de uma política pública devem levar em consideração os respectivos efeitos sobre a parcela da população beneficiada, estimando os sacrifícios que podem ser suportados pela sociedade nesse sentido.

Se o objetivo do direito, na ótica da AED, é analisar as normas legais de modo a promover eficiência, implicando a maximização do bem-estar social, na transferência da implementação de políticas públicas pelo Terceiro Setor, essa premissa também é válida, uma vez que as atividades se inserem na perspectiva da economia e da modificação da realidade social (TABAK, 2015).

Um aspecto a ser observado quando da contratação da administração pública com o particular se refere às falhas de mercado, verificáveis quando os mecanismos de mercado, não regulados pelo Estado e deixados a seu livre funcionamento, originam resultados econômicos ineficientes ou indesejáveis socialmente. Essas falhas são provocadas pelas imperfeições do mercado, notadamente, pela assimetria das informações ou por informação incompleta dos agentes econômicos, bens públicos e pelas externalidades, que são "impactos negativos causados pelo sistema econômico." (ANDRADE, 2008, p. 3).

Associados a uma transação, existem contratos explícitos ou implícitos aos quais se soma um conjunto de custos, de obtenção de informação, de negociação, de elaboração do contrato, de monitoração, de assegurar a implementação dos termos do contrato e outros (PEREIRA, 1999).

Sobre a assimetria das informações, essa é um óbice e impedimento às relações econômicas, bem como ao desenvolvimento de políticas públicas eficientes. Ela deriva do desconhecimento de todos os possíveis eventos futuros que podem afetar uma transação, de forma a tornar improvável que soluções tomadas no curso do processo possam ser as que melhor atendam ao interesse público (SILVA; AGUIAR; TABAK, 2015).

Em geral, as políticas públicas devem passar por uma análise de custo-benefício, o que nem sempre é suficiente, pois:

Podem existir outros objetivos para as proposições ou políticas públicas além da busca da eficiência e equidade. Nesse sentido, a análise de custo-benefício é um elemento importante, mas não necessariamente deve ser visto como exclusivo. 
O princípio chave é o de que todos os custos e benefícios devem ser levados em conta. Se não for possível quantificá-los, deve-se ao menos explicitá-los e descrevê-los tão bem quanto possível. Assim, as decisões a serem tomadas pelos formuladores de políticas serão mais bem informadas (TABAK, 2015, p. 17).

Essa análise visa a maximizar o bem-estar da sociedade, por meio dos resultados das referidas políticas, e "pressupõe a confrontação de todos os custos e benefícios gerados pela introdução" delas na sociedade e no mercado. Conforme Tabak (2015, p. 19), a questão é que "as políticas públicas podem gerar conflitos distributivos", ganhos líquidos para determinada parte ou setores da população e perdas para outros. Elas também podem envolver uma redistribuição de recursos na economia, uma vez que, de modo geral, projetos de lei, programas e políticas públicas "geram efeitos redistributivos."

As dificuldades de se valorarem os benefícios e os custos relacionados com a política pública a ser desenvolvida podem ser supridas com a aplicação de metodologias da AED, como valoração contingencial, modelos hedônicos de apreçamento e taxas de desconto, entre outros.

A valoração contingencial é uma metodologia que se utiliza de surveys - ou obtenção de informações quantitativas sobre grupos específicos de pessoas - para mensurar a disposição da população para pagar e para receber os benefícios (advindos das políticas públicas, por exemplo). A valoração contingencial, segundo Tabak (2015), é utilizada para valorar benefícios e custos quando se introduzem objetivos que não possuem valor de mercado, como construção de hospital ou de presídio, ação de essencial utilidade para a sociedade. Nos modelos hedônicos de apreçamento para avaliação de custos e de benefício da uma política pública, os valores podem ser inferidos por meio da observação do comportamento do mercado. Essa metodologia deve ser aplicada com cuidado, devido à importância, muitas vezes, dada à renda relativa pelos agentes econômicos, cujo foco pode criar vieses nas decisões e nas distorções dos resultados. A metodologia das taxas de desconto diz respeito à mensuração das preferências individuais por meio das taxas de juros da economia. Calculam-se taxas de desconto nesse sentido, e o resultado vai representar uma recompensa "pelo adiamento de consumo presente, propiciando maior consumo futuro." Taxas de desconto altas indicam que a sociedade valoriza mais o presente que o futuro. "A taxa de desconto utilizada no processo de decisão na análise de custo e benefício de políticas públicas deve refletir o custo de oportunidade da sociedade." (TABAK, 2015, p. 17-19).

Diante disso, Tabak destaca o seguinte: mesmo que se possa concluir pela implementação das políticas públicas após a análise dos respectivos custos e dos benefícios, seus resultados podem não ser eficientes no sentido de Kaldor-Hick-"os benefícios são maiores que os custos para a sociedade"- mas serem no sentido de Pareto - "alguns estão em situação melhor e não houve piora na situação dos outros". "Embora o conceito de eficiência de Kaldor-Hicks exija que a maioria se beneficie com determinada medida e que possa haver agentes que saem perdendo, é sempre possível realizar uma redistribuição dos recursos de forma a tornar essa medida eficiente no sentido de Pareto.” (TABAK, 2015, p. 8-9). 
Em uma pesquisa que avaliou os resultados de três programas da política de governo "Programa Fome Zero" (demandas por cisternas, restaurantes comunitários e aquisição de alimentos da agricultura familiar), implementados em parcerias público-privadas, Kanté (2009) se utilizou dos conceitos de eficiência, efetividade e eficácia e apresentou resultados quantitativos dos beneficiados, detectou desvios de finalidade, problemas de comunicação e outros, relacionados ora com o próprio Governo Federal, ora com as estruturas locais. Porém, segundo a ótica da eficiência de Kaldor-Hicks e de Pareto, quando houve ganhadores e perdedores, esses não foram avaliados. $O$ trabalho não envolveu a perspectiva da AED.

No campo da teoria econômica, normalmente, as análises de custos e benefícios "são baseadas em critérios de eficiência extraídos do Teorema Kaldor-Hicks (ou Melhoria Potencial de Pareto) e do Teorema de Pareto (Ótimo de Pareto).” (CARDOSO, 2015, p. 301). O critério de Kaldor-Hicks prevê que as políticas públicas geram tanto ganhadores como perdedores, "mas propõe que haja um ganho maior aos ganhadores que uma perda maior para os perdedores" (CARDOSO, 2015, p. 302). Já o critério de eficiência proposto por Pareto tenta resolver o problema da escolha de qual política a se adotar, almejando uma solução que simplesmente procure a máxima satisfação de um maior número de pessoas (KANTÉ, 2009).

No caso da pesquisa de Kanté, especificamente, o programa de cisternas foi implementado pelo Ministério do Desenvolvimento Social (MDS), em parceria com o Programa Articulação do Semiárido (ASA), uma entidade articuladora e apartidária, formada por organizações da sociedade civil, e com a "Associação Programa Um Milhão de Cisternas para o Semiárido (AP1MC)", entidade jurídica de direito privado, sem fins lucrativos, integrante do Terceiro Setor (KANTÉ, 2009).

A implementação do programa partiu não só das demandas sociais - levar água para a região do semiárido brasileiro -, mas também se apoiou, em grande parte, na estrutura encontrada para a realização das ações desenvolvidas pela ASA. O governo estabeleceu uma parceria com organizações em funcionamento, criadas em governos anteriores, para a operacionalização de um dos programas da política Fome Zero (KANTÉ, 2009).

Essa possibilidade de transferência da execução de políticas públicas (ou programas, que, nesse caso, seguem os mesmos parâmetros das políticas, inclusive quanto à respectiva avaliação) para entidades do Terceiro Setor justifica-se sob análise econômica, também, em situações nas quais, não tendo a expertise necessária, o Estado transfere para o ente privado a execução de uma política pública, com os objetivos e os custos previamente determinados. Atende-se, assim, ao critério de eficiência tanto na ótica de Pareto como na de Kaldor-Hicks.

\subsection{MENSURAC̣ÃO DE CUSTOS E DE BENEFÍCIOS}

Uma metodologia de mensuração de custos e de benefícios na implementação de programas ou políticas públicas é a de Hart (2003). Para se mensurar tais custos e benefícios nesses casos, Hart (2003) utiliza um modelo que pode ser empregado em qualquer situação 
na qual o administrador público tenha de optar por entregar ou não a execução de um serviço ao particular e, em o fazendo, qual o melhor modelo de gestão.

Tomando por base uma Parceria Público-Privada (PPP) para a construção de instalações e para a prestação de serviços, como a construção de uma prisão e a prestação dos respectivos serviços, em uma primeira hipótese, o governo pode contratar um ente privado. Em uma segunda hipótese, em uma disposição "convencional”, o governo contrata o construtor para construir a prisão e, mais tarde, outro ente privado para administrá-la.

Nessa segunda hipótese, o contrato entre o governo e o construtor é fixado na data 0. A prisão é construída entre datas 0 e 1 , e a prisão é operada entre as datas 1 e 2 . O contrato especifica as características básicas da prisão que devem ser entregues na data 1 (no caso da prestação convencional) e os serviços prisionais básicos que devem ser prestados entre as datas 1 e 2 (no caso de uma PPP). Em cada caso, o contrato é assumido como incompleto, no sentido de que o construtor pode modificar a natureza da prisão ou a natureza dos serviços penitenciários de várias maneiras, sem violar o contrato. Especificamente, o construtor pode fazer duas espécies de investimentos, relacionados à construção e à operacionalização dos serviços, que têm consequências para os custos e os benefícios do funcionamento da prisão entre as datas 1 e 2 .

Podem-se interpretar esses investimentos da seguinte forma: o investimento na construção pode ser produtivo, o que torna a prisão mais atraente e mais fácil de ser construída, correspondendo a um edifício de qualidade superior e, a princípio, menos lucrativo para o construtor. Por outro lado, pode-se desenvolver um investimento improdutivo que reduz a qualidade na construção e em seus custos, embora venha a impactar a operação do serviço subsequente, tornando mais dispendiosa sua contratação. Por exemplo, afirma Hart que, no processo de construção da prisão, o construtor pode perceber que pode instalar uma cerca elétrica que reduz a probabilidade de fugas. Isso reduz os custos operacionais das prisões, uma vez que menos guardas têm de ser contratados. Mas pode não ter sido previsto pelo governo e vai impactar nos custos de construção.

Veja-se o seguinte: se o governo não possui todas as informações do contrato, mas os entes privados as detêm, o governo contrata um construtor na data 0 para construir uma prisão básica para o preço PO. Na data 1, o governo leiloa o contrato para operar a prisão. Se houver um ambiente competitivo de empreiteiras, o governo pagará ao operador da prisão um preço igual ao seu custo operacional, havendo, assim, equilíbrio do investimento de operação com o retorno esperado pelo particular. Nessa perspectiva, a solução é simples: o construtor constrói a prisão com o menor custo possível, não internalizando o custo da operação.

Entretanto, se o governo oferece um contrato na data 0 , que especifica a qualidade básica do serviço a ser prestado entre as datas 1 e 2 e um preço P no mesmo contrato, o construtor internaliza, agora, o custo da prestação de serviços, arcando com eventuais custos decorrentes de uma construção improdutiva. 
Sob o sistema clássico de separação, o construtor não internaliza o custo operacional. Em contrapartida, sob agrupamento obra/serviço, o construtor internaliza os custos de operacionalização e, como resultado, torna o investimento mais produtivo do que o improdutivo, visto que ele mesmo arcará com os custos adicionais decorrentes da má construção.

O modelo de Hart leva a uma conclusão simples: a prestação convencional, de separação da contratação de obra e serviço, é boa se a qualidade da construção do edifício pode ser bem especificada, enquanto a qualidade do serviço não pode ser. Nessas condições, o subinvestimento no âmbito da obra será possivelmente detectado, enquanto o sobrepreço na operação do serviço em PPP pode não ser.

Em contrapartida, a contratação de serviço público precedido de obra pública ou em PPP é boa se a administração tem condições de especificar a qualidade do serviço no contrato inicial (boas medidas de desempenho que podem ser utilizadas para recompensar ou penalizar o prestador de serviços), mas tem dificuldade de avaliar a qualidade na construção. Nessas condições, o subinvestimento na obra sob a provisão convencional pode ser um problema, enquanto o sobrepreço na prestação do serviço contratado não é.

Portanto, o sucesso da execução de uma política pública depende, em grande parte, de sua estruturação e das circunstâncias levadas em consideração em seu planejamento - tal como descrito no item relativo à sua criação, implementação e dificuldades - e na definição dos parâmetros de execução - como os exemplificados anteriormente, relativos à AED.

$\mathrm{O}$ aspecto funcional inovador de qualquer modelo de estruturação do poder político caberá justamente às políticas públicas. Em relação a elas, mais importantes que os objetivos ou as metas temporais fixadas, será o processo de sua realização, a partir dos parâmetros fixados em lei. Em parte, esse é o processo político, cuja legitimidade e cuja "qualidade decisória", no sentido da clareza das prioridades e dos meios para realizá-las, estão na razão direta do amadurecimento da participação democrática dos cidadãos. Em grande parte, porém, o sucesso da política pública, qualquer que seja ela, está relacionado com a qualidade do processo administrativo que precede a sua realização e que a implementa. As informações sobre a realidade a transformar, a capacitação técnica e a vinculação profissional dos servidores públicos, a disciplina dos serviços públicos (BUCCI, 1997, p. 97).

Conforme Hart, pode-se argumentar que prisões e escolas se enquadram no primeiro caso: a contratação do edifício é relativamente simples, enquanto a contratação do serviço pode não ser. Por outro lado, hospitais podem pertencer ao segundo caso: embora a especificação da qualidade do serviço esteja longe de ser direta, pode ser mais fácil apresentar medidas de desempenho razoáveis sobre como os pacientes são tratados do que especificar a construção de um edifício muito complexo.

\section{CONSIDERAÇÕES FINAIS}

Procurou-se destacar instrumentos que podem servir de parâmetro para a avaliação da eficiência na implementação de políticas públicas no Brasil, sendo a AED o campo de 
análise dessas ferramentas que visam a avaliar os respectivos custos e benefícios como forma de se mensurar os possíveis resultados.

A transferência da implementação de políticas públicas para o Terceiro Setor suscita ainda questionamentos de ordem prática, haja vista as implicações no desenvolver de seus processos, que vão desde o conhecimento específico da natureza do problema e de sua extensão até as condições encontradas nos locais, objeto das políticas, no momento de sua execução, ou seja, há um quase “desaparelhamento” institucional e estrutural com o qual o Terceiro Setor se defronta, mas que, independente disso, tem de levar a cabo sua responsabilidade. Além disso, há o "lidar" com os recursos públicos e o controle das ações, o que requer conhecimento e até expertise, no sentido de maximizar resultados com menos recursos.

Ressalte-se que a delegação da execução de serviços públicos para entidades privadas não se encontra na estrutura da administração pública, significando que, no interesse social, elas passam a receber e a gerir recursos públicos com vistas à execução desses serviços.

Por outro lado, a Reforma do Estado tem na descentralização talvez a única forma ou a mais imediata para solução dos problemas que o Estado não vem conseguindo atender, qual seja, a prestação de serviços de toda ordem à sociedade. Em outras palavras, quer-se dizer que a transferência da implementação de políticas para o Terceiro Setor não é só uma exigência da realidade que se impõe diante de tantas lacunas, mas também uma ação prevista em lei e considerada um dos pilares para o funcionamento da referida Reforma.

Nessa perspectiva, foram descritas as condições processuais das políticas públicas, visando ao seu dimensionamento como tal e apresentados elementos metodológicos da AED que podem auxiliar, principalmente, o Terceiro Setor no cumprimento dessas tarefas.

\title{
METHODOLOGICAL INSTRUMENTS FOR THE ECONOMIC ANALYSIS OF LAW AND EFFICIENCY OF PUBLIC POLICIES EXECUTED BY THE THIRD SECTOR
}

\begin{abstract}
The objective of this paper is to identify methodological instruments of the Economic Analysis of the Law that can contribute to the execution of public policies by the Third Sector, in the search for the efficiency of the former and the latter. The research has as scope the Brazilian State Reform and the model of managerial administration adopted in the 90's (20th century) in replacement of the patrimonialist state and bureaucratic administration. Globalization is a parallel process that indicates, in its context, the keys to development. We present methodological tools for the Economic Analysis of Law, related to efficiency, as well as criteria that allow the evaluation of social costs and social benefits in the implementation of public policies.
\end{abstract}

Keywords: Administrative Reform. Economic Analysis of Law. Public policy. Third sector. 


\section{INSTRUMENTOS METODOLÓGICOS DEL ANÁLISIS ECONOMICO DEL DERECHO Y EFICIENCIA DE LAS POLÍTICAS PÚBLICAS EJECUTADAS POR EL TERCER SECTOR}

\section{RESUMEN}

El presente artículo tiene por objetivo apuntar instrumentos metodológicos del Análisis Económico del Derecho que pueden contribuir a la ejecución de políticas públicas por el Tercer Sector, en la búsqueda de la respectiva eficiencia. La investigación tiene como objetivo la Reforma del Estado brasileño y el modelo de administración gerencial adoptado en la década de los 90 (siglo XX) en sustitución del Estado patrimonialista y la administración burocrática. La globalización es mencionada como un proceso paralelo que indica, en su contexto, las claves para el desarrollo. Los instrumentos metodológicos del análisis económico del derecho, relativos a la eficiencia, se presentan, así como criterios que posibilitan la evaluación de los costos y beneficios sociales en la implementación de políticas públicas.

Palabras clave: Reforma Administrativa. Análisis Económico del Derecho. Políticas públicas. Tercer sector.

\section{REFERÊNCIAS}

ALVAREZ, Alejandro Bugallo. Análise econômica do direito: contribuições e desmistificações. Revista de Direito, Estado e Sociedade, Rio de Janeiro, v. 9, n. 29, p. 49-68, jul./ dez. 2006.

ANDRADE, Daniel Caixeta. Economia e meio ambiente: aspectos teóricos e metodológicos nas visões neoclássica e da economia ecológica. Leituras de Economia Política, v. 14, p. 1-31, ago./dez. 2008.

ARRETCHE, Marta, T. S. Mitos da descentralização: mais democracia e eficiência nas políticas públicas? Revista Brasileira de Ciências Sociais, n. 31, p. 44-66, 2006. Disponível em: <http://www.anpocs.org.br/>. Acesso em: $20 \mathrm{dez} .2017$.

BALAZEIRO, Alberto Bastos. O terceiro setor e o dilema da intermediação ilícita de mão de obra. In: PAES, José Eduardo Sabo (Org.). Terceiro Setor e Tributação. São Paulo: Elevação, 2016. v. 9.

BARBOSA, Evanir Lenhardt. Controle interno da administração pública: instrumento de controle e de gerenciamento. 2002. Monografia - Universidade Federal do Rio Grande do Sul, Porto Alegre, 2002. Disponível em: <www.tce.rs.gov.br>. Acesso em: 25 jan. 2018.

BAUMAN, Zigmunt. Globalização: as consequências humanas. Tradução Marcus Penchel. Rio de Janeiro: Jorge Zahar, 1999. 
BRASIL. Ministério da Administração Federal e Reforma do Estado. Secretaria da Reforma do Estado. Organizações sociais. 5. ed. Brasília: Ministério da Administração e Reforma do Estado, 1998.

- Ministério da Administração Federal e Reforma do Estado. A Nova Política de Recursos Humanos. Brasília: MARE, 1997.

. Supremo Tribunal Federal. Ação Direta de Inconstitucionalidade no 1.923. Relator: Ministro Ayres Britto. Julgamento: 16 abr. 2015. Órgão Julgador: Tribunal Pleno. DOU, Brasília, 17 dez. 2015. Disponível em: <http://www.stf.jus.br/arquivo/cms/noticiaNoticiaStf/anexo/Voto_ADI1923LF.pdf>. Acesso em: 25 jan. 2018.

BRITO, Maurício Ferreira. Constitucionalização das Contratações das Organizações Sociais na Área de Saúde. A decisão do STF à luz da eficiência e da probidade no serviço público. In: PAES, José Eduardo Sabo (Org.). Terceiro Setor e Tributação. São Paulo: Elevação, 2016. v. 9.

BUCCI, Maria Paula Dallari. Políticas públicas e direito administrativo. Revista de Informação Legislativa, Brasília, v. 34, n. 133, p. 89-98, 1997.

CARDOSO, Fernando Henrique. Plano Diretor da Reforma do Aparelho do Estado. Brasília: Presidência da República, 1995.

CARDOSO, Germano Bezerra. Análise econômica do direito, políticas públicas e consequências. Revista Jurídica da Presidência, Brasília, v. 17, n. 112, p. 293-313, jun./set. 2015.

COSTA, Bruno L. Diniz. As mudanças na agenda das políticas sociais no Brasil e os desafios da inovação. In: CARVALHO, Alysson et al. (Org.). Políticas públicas. Belo Horizonte: UFMG, 2002.

DIAS, Maria Tereza Fonseca. Terceiro Setor e Estado: legitimidade e regulação: por um novo marco jurídico. Belo Horizonte: Fórum, 2008.

EASTON, David. Modalidades de análise política. Rio de Janeiro: Zahar, 1970.

FAORO, Raimundo. Os Donos do poder: formação do patronato político brasileiro. 11. ed. São Paulo: Globo, 1997. v. 1.

FOLLONI, André; YAZBEK, Cristiano Lisboa. Eficiência Tributária do Estado e Retorno de Bem-Estar à Sociedade. Revista Opinião Jurídica, Fortaleza, v. 11, n. 15, p. 26-39, jan./ dez. 2013.

GICO JUNIOR, Ivo T. Metodologia e Epistemologia da Análise Econômica do Direito. Economic analysis of law Review, v. 1, n. 1, p. 7-33, 2010.

GONÇALVES, Oksandro Osdival; RIBEIRO, Marcelo Miranda. Incentivos fiscais: uma perspectiva da Análise Econômica do Direito. Economic Analysis of Law Rewiew, v. 4, n. 1, 2013. 
HABERMAS, Jürgen. Direito e democracia entre facticidade e validade. Tradução Flávio Beno Siebeneichler. Rio de Janeiro: Tempo Brasileiro, 2012.

HART, Oliver. Incomplete Contracts and Public Ownership: Remarks, and an application to Public-Private Partnerships. The Economic Journal, v. 113, n. 486, 2003.

HOBSBAWM, Eric. A era dos extremos: o breve século XX 1914-1991. Tradução Marcos Santarita. 2. ed. São Paulo: Companhia das Letras, 1995.

HOLMES JUNIOR, Oliver Wendell. The path of the law. Harvard Law Rewiew, n. 457, 1897.

HUDSON, Mike. Administrando organizações do terceiro setor: o desafio de administrar sem receita. São Paulo: Makron Books, 1999.

KANTÉ, Mamadou Lamine. Programa Fome Zero: uma avaliação de sua implementação. 2009. 117 f. Dissertação (Mestrado em Ciências Políticas) - Universidade de Brasília, Brasília, 2009.

KEYNESIANISMO: o que é, principais características, resumo, conceito, doutrina econômica, intervenção estatal na economia. Disponível em: <https://www.suapesquisa.com/ economia/>. Acesso em: 20 dez. 2017.

KOSSMANN, Edson Luís. A constitucionalização do princípio da eficiência na administração pública. Porto Alegre: Sergio Antonio Fabris, 2015.

LUSTOSA, Paulo Henrique. Políticas públicas e assistência social: um preâmbulo para a discussão do Plano Municipal de Assistência Social da Prefeitura Municipal de Fortaleza (1998/2002). 2006. Disponível em: <www. ibrad.org.br>. Acesso em: 27 dez. 2017.

MAZETTO, Flávio Eduardo. Estado, políticas públicas e neoliberalismo: um estudo teórico sobre as parcerias-público-privadas. Caderno de Estudos Interdisciplinares, Minas Gerais, p. 1-21, 2015.

MERCADO, Pedro. El Análisis Económico del Derecho: una reconstrucción teórica. Madrid: Centro de Estudios Constitucionales, 1994.

MITCHELL, Willian, C.; SIMMONS, Randy, T. Para além da política: mercados, bem-estar social e o fracasso da burocracia. Tradução Jorge Ritter. Rio de Janeiro: TOPBOOKS, 2003.

PAES, José Eduardo Sabo. As fundações, associações e entidades de interesse social. 8. ed. Rio de Janeiro: Forense, 2013.

PARANÁ. Secretaria do Meio Ambiente e Recursos Hídricos. O que são políticas públicas? Disponível em: 〈www.meio ambiente.pr.gov.br/arquivos〉. Acesso em: 28 jan. 2018.

PEREIRA, Paulo Trigo. Governabilidade, grupos de pressão e o papel do Estado. In: ENCONTRO NACIONAL DE CIÊNCIA POLÍTICA, 1999. Lisboa. Anais... Lisboa: Fundação Calouste Gulbenkian, dez. 1999. p. 22. Disponível em: <https://pascal.iseg.ulisboa. pt>. Acesso em: 17 abr. 2017. 
PEREIRA, Luiz Carlos Bresser. A reforma do aparelho do Estado e a Constituição brasileira. Texto para Discussão, n. 1, p. 3, 1995. Disponível em: <www.bresserpereira.org. br.>. Acesso em: 2 fev. 2018.

PEREIRA, Luiz Carlos Bresser. A reforma do Estado dos anos 90: lógica e mecanismos de controle. Brasília: MARE, 1997. Disponível em: 〈http://bresserpereira.org.br〉. Acesso em: $20 \mathrm{dez} .2017$.

PEREIRA, Luiz Carlos Bresser. Gestão do setor público: estratégia e estrutura para um novo Estado. In: PEREIRA, Luiz Carlos Bresser; SPINK, Peter. (Org.). Reforma do Estado e administração pública gerencial. Rio de Janeiro: FGV, 1998a.

PEREIRA, Luiz Carlos Bresser. A reforma do Estado nos Anos 90: lógica e mecanismos de controle. Lua Nova Revista de Cultura e Política, n. 45, p. 49-95, 1998b. Disponível em: <http://www.bresserpereira.org.br>. Acesso em: 25 jan. 2018.

PEREIRA, Luiz Carlos Bresser. A administração pública gerencial: estratégia e estrutura para um novo Estado. Brasília: ENAP, 2001. Disponível em: <http://repositorio.enap.gov. br>. Acesso em: 20 dez. 2017.

PEREIRA, Luiz Carlos Bresser. A reforma gerencial de 1995. In: CASTOR, Belmiro Valverde J. Burocracia e reforma do Estado. São Paulo: Fundação Conrad Adenauer, $2001 b$.

PEREIRA, Luiz Carlos Bresser. Reforma do Estado e administração pública gerencial. 7. ed. Rio de Janeiro: FGV, 2011.

RIFKIN, Jeremy. Terceira Revolução Industrial. Planeta Sustentável, 2007. Disponível em: <https://edisciplinas.usp.br>. Acesso em: 2 fev. 2018.

ROBINSON, Willian I. Global capitalism theory and emergence of transnational elites. United Nations University: Working Paper, 2010.

RUA, Maria das Graças. Análise de políticas públicas: conceitos básicos. Washington, Indes/BID, 1997.

SARAVIA, Enrique. Introdução à teoria da política pública. In: SARAVIA, Enrique; FERRAREZI, Elisabete. Políticas Públicas. Brasília: ENAP, 2006a. p. 21-42. Disponível em: <www.enap.gov.br/documents>. Acesso em: 20 jan. 2018.

SARAVIA, Enrique. Política pública: dos clássicos às modernas abordagens: orientação para a leitura. In: SARAVIA, Enrique; FERRAREZI, Elisabete. Políticas Públicas. Brasília: ENAP, 2006b. p. 13-18. Disponível em: <www.enap.gov.br/documents>. Acesso em: 20 jan. 2018.

SELEPRIN, Maiquel José. A relação Estado e Terceiro Setor. 2012. Disponível em: <http://www.educadores.pr.gov.br>. Acesso em: 2 fev. 2018. 
SENE, Eustáquio de. Globalização e espaço geográfico. São Paulo: Contexto, 2012.

SILVA, Alexandre Gomes Bezerra da; AGUIAR, Julio Cesar de; TABAK, Benjamin Miranda. Incentivos fiscais capturados pelos oligopólios: uma perspectiva da análise econômica do direito: In: TABAK, Benjamin Miranda; AGUIAR, Julio Cesar de (Org.). Análise econômica do direito: uma abordagem aplicada. Porto Alegre: Nubia Fabris, 2015. SILVA, Raissa Pimentel. Princípio do protetor: beneficiário: por uma justificativa de efetivação à luz da análise comportamental do legislado. Economic Analysis of Law Rewiew, v. 6, n. 2, p. 284-303, 2015.

STRAPASSON, Karoline; PAMPLONA, Danielle Anne. A escolha pública econômica para erradicar a pobreza extrema no Brasil. Revista Brasileira de Políticas Públicas, v. 4, n. 2, p. 47-63, 2014.

SZAZI, Eduardo. Terceiro Setor: regulação no Brasil. São Paulo: Petrópolis, 2003.

TABAK, Benjamin. A análise econômica do direito: proposições legislativas e políticas públicas. Revista de Informação Legislativa do Senado, v. 52, n. 20, p. 321-345, 2015. YANO, Nina Machado; MONTEIRO, Sérgio Marley Modesto. Mudanças institucionais na década de 1990 e seus efeitos sobre a produtividade total dos fatores. 2008. Disponível em: 〈http://www.anpec.org.br/encontro>. Acesso em: 28 dez. 2017. 